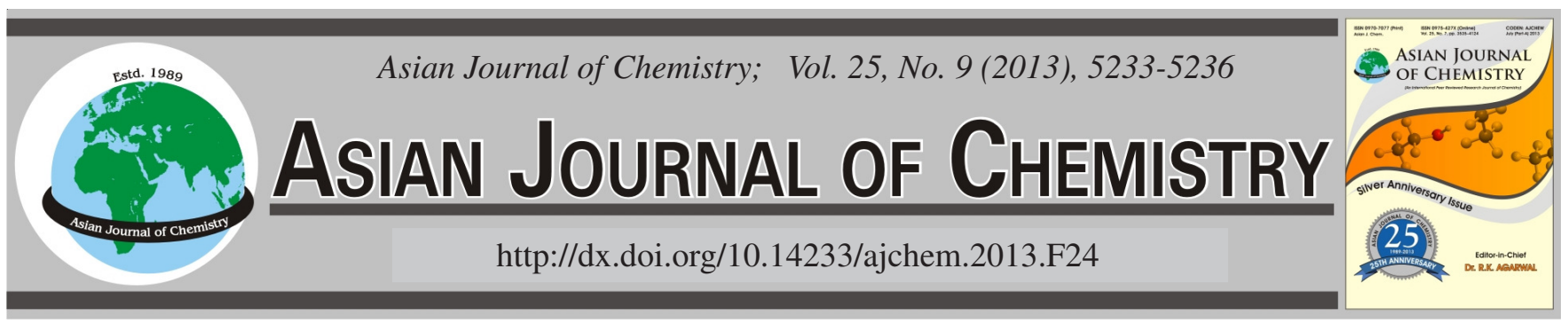

\title{
Adhesion Properties of Styrene-Butadiene-Styrene Triblock Copolymer-Based Pressure-Sensitive Adhesives for Protecting Opto-functionalized Sheets $\dagger$
}

\author{
D.J. Chol, Y.K. Hong and K.H. ChUnG*
}

Department of Polymer Engineering, The University of Suwon, Suwon, Republic of Korea

*Corresponding author: E-mail : khchung@suwon.ac.kr

AJC-13179

\begin{abstract}
Various pressure sensitive adhesives based on the types of tackifier were designed and their physical properties were analyzed. The behaviour of pressure sensitive adhesives transfer on an opto-functionalized sheet was examined. Pressure sensitive adhesives was prepared by adding various tackifiers with different molecular weights and softening points to styrene-butadiene-styrene. The physical properties of pressure sensitive adhesives were analyzed by measuring the peel strength, initial tack, holding power and contact angle obtained after coating the pressure sensitive adhesives onto a polypropylene film. The changes in the physical properties of pressure sensitive adhesives after adding an additional curing agent were also observed at various UV exposure times. The peel strength and initial tack increased with decreasing softening point of tackifier. An increasing trend of pressure sensitive adhesives transfer was also observed with increasing peel strength. In the case where a curing agent was added to the adhesive showing pressure sensitive adhesives transfer, the peel strength and initial tack decreased with increasing UV exposure time and amounts of curing agent, whereas the holding power increased.
\end{abstract}

Key Words: Pressure sensitive adhesives, Opto-functionalized sheet, Styrene-butadiene-styrene, UV curing, Transfer.

\section{INTRODUCTION}

Back light unit, a main component of the light source of liquid crystal displays (LCDs), maintains uniform brightness in the direction of the liquid crystal display panel while having a structure that effectively expresses a range of colour information. The opto-functionalized sheet of back light units with micro-patterns is a material with uni-axially extended PET films in different directions and UV cured ${ }^{1,2}$. A protection film is used to protect the pattern of the opto-functionalized sheet from bending or becoming polluted during manufacturing. Transfer is the most important property of a pressure sensitive adhesive $^{3}$, which is used with the protection film. Transfer is a phenomenon, where pressure sensitive adhesive is left on the opto-functionalized sheets surface when removing the protection film. This transfer causes a change in the adhesion force with time and is considered a major shortcoming in the liquid crystal display industry ${ }^{4}$.

Acryl type pressure sensitive adhesive is unsuitable for use as a pressure sensitive adhesive for protection films because it has polar groups, such as $-\mathrm{COOH}$ and $-\mathrm{OH}$, which are likely to cause the transfer of pressure sensitive adhesive by secondary bonding ${ }^{5}$. On the other hand, rubber type pressure sensitive adhesive is much more stable than acryl pressure sensitive adhesive in terms of transfer when used as a pressure sensitive adhesive of protection film as it is non-polar. SBS (styrene-butadiene-styrene triblock copolymer) has been widely used in the pressure sensitive adhesive industry owing to its economical values and relatively easy manufacture ${ }^{6}$. The double bond of the poly(butadiene) block breaks and crosslink is initiated when SBS is mixed with a photoinitiator and curing agent and exposed to UV light ${ }^{7,8}$.

In this study, the transfer characteristics of pressure sensitive adhesive with various molecular weights and the softening point of a tackifier was investigated. In addition, the changes in adhesion properties with various curing agent concentrations and UV exposure times were also examined.

\section{EXPERIMENTAL}

Materials and pressure sensitive adhesive preparation: Styrene-butadiene-styrene triblock copolymer (SBS) used in this study was supplied by Kumho Petrochemical (KTR-201). Five different tackifiers with varying molecular weights and softening points were obtained from Kolon, as shown in Table1. The tackifiers were a type of aliphatic hydrocarbon resin. The SBS solution and $30 \mathrm{wt}$ \% tackifier solution were prepared 
by dissolving each in toluene. The SBS based pressure sensitive adhesives were prepared by adding varying amounts of tackifier solution to a constant volume of SBS solution. Benzophenone (Acros Organic Co. Ltd.) was used as the photoinitiator and trimethylolpropane mercaptopropionate(TRIS; Sigma-Aldrich Co. Ltd.) was used as the curing agent for UV curing. The pressure sensitive adhesives were coated on polypropylene films to a coating thickness of $16 \mu \mathrm{m}$. The pressure sensitive adhesive tape for protecting the opto-functionalized sheet was prepared by drying it for one minute at $100{ }^{\circ} \mathrm{C}$.

TABLE-1

TYPES OF TACKIFIERS USED IN THIS STUDY

\begin{tabular}{ccc}
\hline Trade name & Softening point $\left({ }^{\circ} \mathrm{C}\right)$ & MW $(\mathrm{g} / \mathrm{mol})$ \\
\hline A-1100 & 100 & 1850 \\
T-3100 & 98 & 2090 \\
C-1100 & 100 & 2850 \\
T-1080 & 87 & 2000 \\
T-1095 & 95 & 1890 \\
\hline
\end{tabular}

Physical properties of pressure sensitive adhesive: The ball tack of the manufactured pressure sensitive adhesive tape for protecting the opto-functionalized sheet was measured using a ball tack tester (QM2000B, QMESYS Co. Ltd.) according to KS T1028. The ball tack was measured by laying the pressure sensitive adhesive tape to a $30^{\circ}$ slope with its adhesive surface facing up and rolling a steel ball. The ball tack of pressure sensitive adhesive was recorded using a steel ball number with the maximum diameter that stopped at the adhesive surface from a specific height.

The pressure sensitive adhesive tape with a width of $25 \mathrm{~mm}$ was adhered to a PET film by rolling a $2 \mathrm{~kg}$ rubber roller back and forth twice. The peel strength was measured using a peel strength tester (PFG 10N, Mecmesin) at a rate of $300 \mathrm{~mm} / \mathrm{min}$ for $2 \mathrm{~h}$ after adhering the pressure sensitive adhesive tape.

The holding power of the pressure sensitive adhesive tape was determined by measuring the time it took for the pressure sensitive adhesive tape to detach when a $500 \pm 10 \mathrm{~g}$ load was applied to pressure sensitive adhesive tape, $25 \times 25 \mathrm{~mm}$ in size, which had been adhered to a PET film using a $2 \mathrm{~kg}$ rubber roller.

\section{RESULTS AND DISCUSSION}

To examine the change in adhesion property according to the tackifier molecular weight, 3 types of tackifiers with similar tackifier characteristics and softening points and various molecular weights were selected. The peel strength, initial tack and holding power experiments were then conducted. The results are shown in Fig. 1. All three types of pressure sensitive adhesive showed an increase in peel strength with increasing tackifier content. The higher transfer behaviour of pressure sensitive adhesive occurred from $40 \mathrm{wt}$ \% tackifier. In addition, the fracture mode changed from interfacial failure to cohesive failure, indicating an increase in peel strength. Tables 2 and 3 present the results of the initial tack and holding power experiments: the initial tack increased with increasing tackifier content. The holding power increased with increasing tackifier content but the holding power was affected more by the polymer than the tackifier. Therefore, its adhesion property changed slightly with varying tackifier contents. According to the results, the molecular weight of the tackifier was not an important factor on the adhesion property of pressure sensitive adhesive. This might be due to the fact that the tackifier was a low molecular weight substance, approximately 1000-2000 g/mol and the difference of molecular weight of tackifiers was not great.

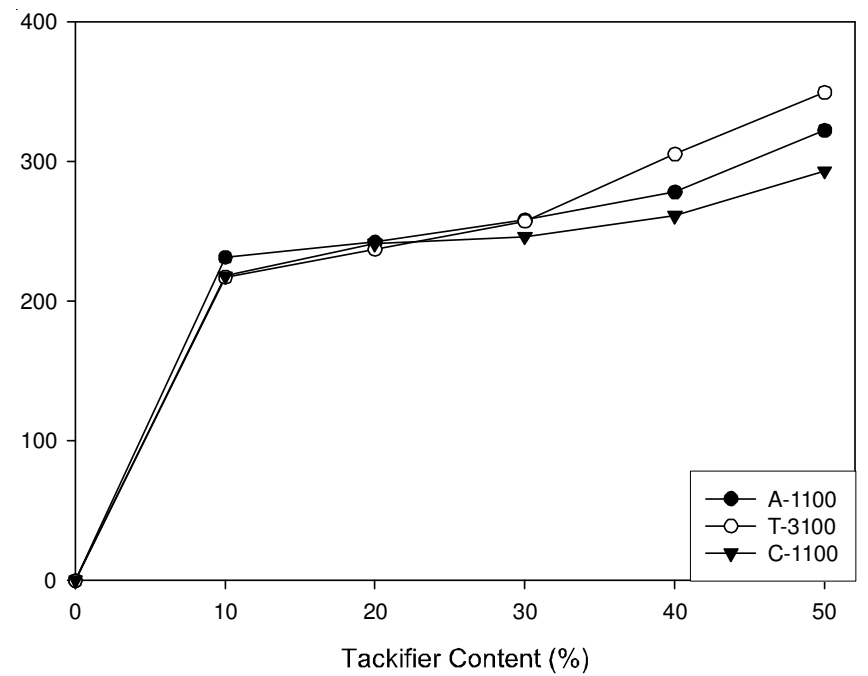

Fig. 1. Peel strength of pressure sensitive adhesive with various molecular weights of the tackifiers

TABLE-2

BALL TACK OF PRESSURE SENSITIVE ADHESIVES WITH VARIOUS MOLECULAR WEIGHTS OF TACKIFIERS

\begin{tabular}{cccccc}
\hline Type of & \multicolumn{5}{c}{ Tackifier content (\%) } \\
\cline { 2 - 6 } tackifier & 10 & 20 & 30 & 40 & 50 \\
\hline A-1100 & No.3 & No.3 & No.4 & No.6 & No.6 \\
T-3100 & No.4 & No.5 & No.5 & No.7 & No.9 \\
C-1100 & No.3 & No.4 & No.4 & No.5 & No.6 \\
\hline
\end{tabular}

TABLE-3

HOLDING POWER OF PRESSURE SENSITIVE ADHESIVES WITH VARYING MOLECULAR WEIGHTS OF THE TACKIFIERS

\begin{tabular}{cccccc}
\hline \multirow{2}{*}{$\begin{array}{c}\text { Type of } \\
\text { tackifier }\end{array}$} & \multicolumn{5}{c}{ Tackifier content (\%) } \\
\cline { 2 - 5 } & 10 & 20 & 30 & 40 & 50 \\
\hline A-1100 & $200 \mathrm{~min}$ & $210 \mathrm{~min}$ & $230 \mathrm{~min}$ & $250 \mathrm{~min}$ & $250 \mathrm{~min}$ \\
$\mathrm{~T}-3100$ & $220 \mathrm{~min}$ & $230 \mathrm{~min}$ & $240 \mathrm{~min}$ & $240 \mathrm{~min}$ & $260 \mathrm{~min}$ \\
$\mathrm{C}-1100$ & $180 \mathrm{~min}$ & $200 \mathrm{~min}$ & $210 \mathrm{~min}$ & $240 \mathrm{~min}$ & $240 \mathrm{~min}$ \\
\hline
\end{tabular}

Fig. 2 shows the adhesion properties of pressure sensitive adhesive with various softening points of tackifiers. The peel strength increased with increasing tackifier content. Moreover, with a tackifier content of $40 \mathrm{wt} . \%$, higher transfer occurred and the peel strength increased rapidly. Tables 4 and 5 show the ball tack test results and holding power test results, respectively. The initial tack also increased with increasing tackifier content, whereas the holding power had little effect. On the other hand, the peel strength and initial tack decreased with increasing softening point of the tackifier. This is caused by the decrease in wettability with the substrate due to hardening of the adhesive layer with increasing tackifier softening point.

Pressure sensitive adhesives with tackifiers of varying molecular weight showed that transfer occurred with all three types of pressure sensitive adhesives. On the other hand, the pressure sensitive adhesive containing tackifiers with increasing 
softening points showed a decrease in transfer and hardening of the pressure sensitive adhesive layer. These results show that transfer is affected more by the softening point than the molecular weight of the tackifier and that the possibility of transfer decreases with increasing softening point.

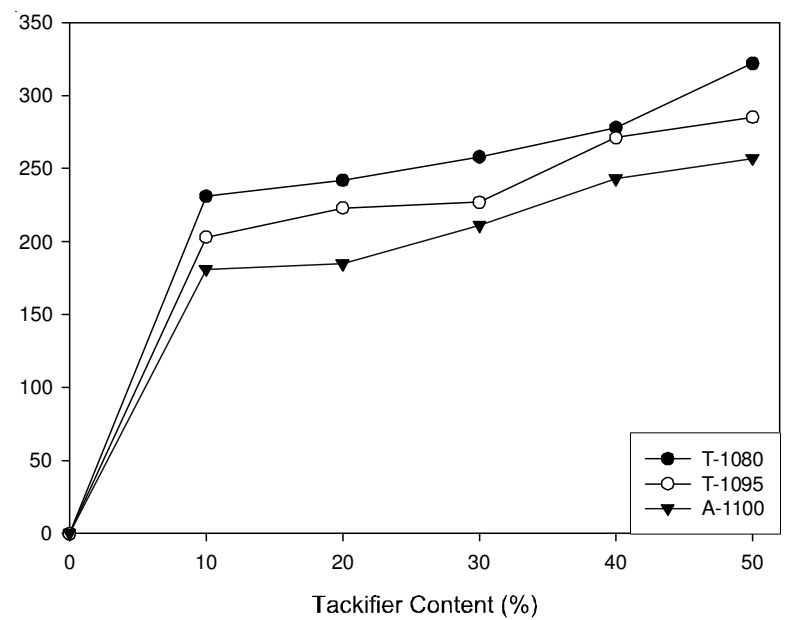

Fig. 2. Peel strength of pressure sensitive adhesive with various softening points of the tackifiers

TABLE-4

BALL TACK OF PRESSURE SENSITIVE ADHESIVES WITH VARIOUS SOFTENING POINTS OF THE TACKIFIERS

\begin{tabular}{cccccc}
\hline Type of & \multicolumn{5}{c}{ Tackifier content (\%) } \\
\cline { 2 - 6 } tackifier & 10 & 20 & 30 & 40 & 50 \\
\hline T-1080 & No.5 & No.5 & No.6 & No.7 & No.8 \\
T-1095 & No.3 & No.3 & No.5 & No.7 & No.7 \\
A-1100 & No.2 & No.3 & No.4 & No.5 & No.5 \\
\hline
\end{tabular}

TABLE-5

HOLDING POWER OF PRESSURE SENSITIVE ADHESIVES WITH VARIOUS SOFTENING POINTS OF THE TACKIFIERS

\begin{tabular}{cccccc}
\hline \multirow{2}{*}{$\begin{array}{c}\text { Type of } \\
\text { tackifier }\end{array}$} & \multicolumn{4}{c}{ Tackifier content (\%) } \\
\cline { 2 - 6 } T-1080 & 10 & 20 & 30 & 40 & 50 \\
\hline $\mathrm{T}-1095$ & $200 \mathrm{~min}$ & $210 \mathrm{~min}$ & $230 \mathrm{~min}$ & $250 \mathrm{~min}$ & $250 \mathrm{~min}$ \\
$\mathrm{~A}-1100$ & $210 \mathrm{~min}$ & $210 \mathrm{~min}$ & $240 \mathrm{~min}$ & $250 \mathrm{~min}$ & $260 \mathrm{~min}$ \\
& & & $230 \mathrm{~min}$ & $250 \mathrm{~min}$ \\
\hline
\end{tabular}

Curing of pressure sensitive adhesive by UV is initiated by the photoinitiator that produces a radical when exposed to UV light. The radical attacks the double bond of a butadiene group of SBS and initiates UV curing. The curing of SBS can be confirmed by examining the characteristic peak for butadiene $-\mathrm{C}=\mathrm{C}$ at $910 \mathrm{~cm}^{-1}$ and $-\mathrm{C}=\mathrm{C}-$ at $964.7 \mathrm{~cm}^{-1}$. Fig. 3 shows the characteristic peak of the butadiene block and the UV-curing mechanism of SBS. Fourier transform infrared (FT-IR) spectroscopy was used to determine if a decrease in these peaks indirectly indicates that curing occurred. Fig. 4 shows the FTIR spectra of pressure sensitive adhesive with various curing agent contents. The UV lamp used in this study was a high pressure mercury UV lamp $600 \mathrm{~W}$ (power: $300 \mathrm{Mw} / \mathrm{cm}^{2}$, overall length:100 nm). The amount of benzophenone was $1 \mathrm{wt} . \%$. The $\mathrm{C}=\mathrm{C}$ double bond peak at $910 \mathrm{~cm}^{-1}$ and $964.7 \mathrm{~cm}^{-1}$ decreased with increasing content of curing agent.

Fig. 5 shows the results of the peel strength of UV-cured pressure sensitive adhesive with various UV exposure times and curing agent contents. The photoinitiator content was kept

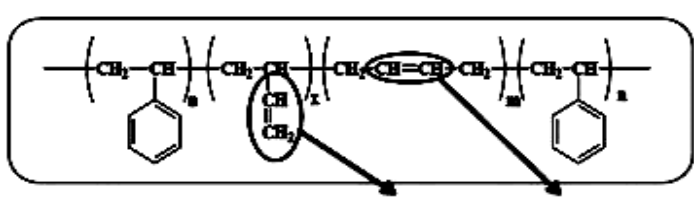

Characteristic peak of $910.8 \mathrm{~cm}^{-1}, 964.7 \mathrm{~cm}^{-1}$

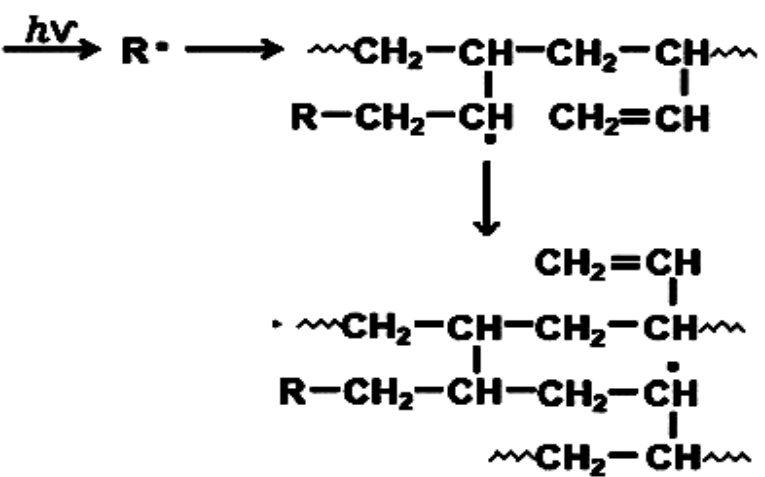

Fig. 3. Butadiene block's characteristic peak and UV-curing mechanism of SBS

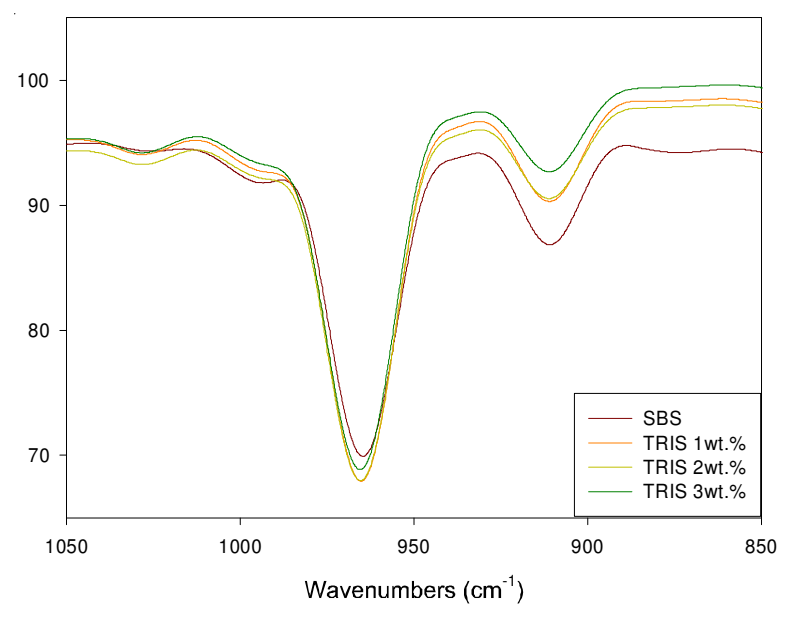

Fig. 4. FT-IR spectra with various amounts of curing agent (BP 1wt. \%)

constant at $1 \mathrm{wt} \%$, whereas the curing agent content was adjusted to 1, 2 and 3 wt. \% with different UV exposure times. The pressure sensitive adhesive hardened with increasing curing agent content and the peel strength decreased. In addition, with increasing UV exposure time, the degree of curing increased, the peel strength decreased and curing was completed at approximately $60 \mathrm{sec}$ where the peel strength remains constant. Tables 6 and 7 present the ball tack test and holding power test results, respectively. The initial ball tack decreased with increased curing agent content and UV exposure time. This is probably due to hardening of the layer with increasing degree of curing. The holding power test revealed an increase in holding power with increasing curing agent content and UV exposure time. Pressure sensitive adhesive increased the cohesive strength with increasing degree of curing. Figs. 6 and 7 show failure surface images of a PET film after the peel strength test with different UV exposure times and different curing agent contents to confirm the transfer characteristics. The surface images were observed by optical microscopy (Xi-cam, x300). Transfer occurred with pressure sensitive adhesives exposed to UV for $20 \mathrm{sec}$ due to incomplete curing. On the other hand, a decrease in transfer can be observed with increasing curing agent content. Transfer did not occur in any 
of the three types of pressure sensitive adhesives when they were exposed to UV light for more than $60 \mathrm{sec}$.

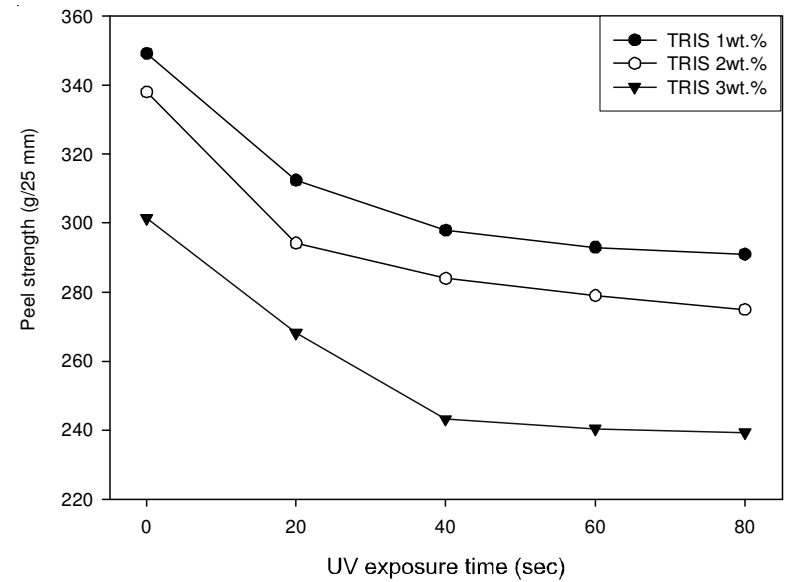

Fig. 5. Peel strength of UV-cured pressure sensitive adhesive with various UV exposure times and curing agent contents

TABLE-6

BALL TACK OF UV CURED PRESSURE SENSITIVE ADHESIVES WITH VARIOUS UV EXPOSURE TIMES AND CURING AGENT CONTENTS

\begin{tabular}{cccccc}
\hline Content of curing & \multicolumn{5}{c}{ UV-exposure time (sec) } \\
\cline { 2 - 6 } agent (wt. \%) & 0 & 20 & 30 & 60 & 80 \\
\hline 1 & No.8 & No.7 & No.7 & No.6 & No.6 \\
2 & No.8 & No.6 & No.5 & No.5 & No.5 \\
3 & No.6 & No.4 & No.3 & No.2 & No.2 \\
\hline
\end{tabular}

\begin{tabular}{|c|c|c|c|c|c|}
\hline \multicolumn{6}{|c|}{$\begin{array}{c}\text { TABLE-7 } \\
\text { HOLDING POWER OF UV CURED PRESSURE SENSITIVE } \\
\text { ADHESIVES WITH VARIOUS UV EXPOSURE } \\
\text { TIMES AND CURING AGENT CONTENTS }\end{array}$} \\
\hline \multirow{2}{*}{$\begin{array}{l}\text { Content of } \\
\text { curing agent } \\
\text { (wt. \%) }\end{array}$} & \multicolumn{5}{|c|}{ UV-exposure time (sec) } \\
\hline & 0 & 20 & 30 & 60 & 80 \\
\hline 1 & $260 \mathrm{~min}$ & $290 \mathrm{~min}$ & $330 n$ & $350 \mathrm{~min}$ & 350 \\
\hline 2 & $270 \mathrm{~min}$ & $320 \mathrm{~min}$ & $350 \mathrm{~min}$ & $360 \mathrm{~min}$ & $360 \mathrm{~min}$ \\
\hline 3 & $300 \mathrm{~min}$ & $340 \mathrm{~min}$ & $370 \mathrm{~min}$ & $390 \mathrm{~min}$ & $400 \mathrm{~min}$ \\
\hline
\end{tabular}

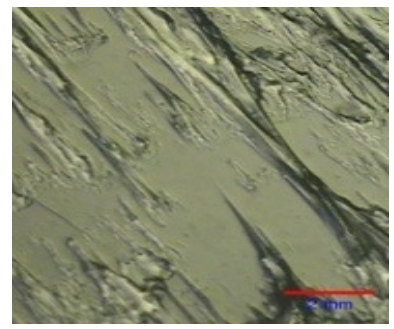

TRIS 1wt.\%

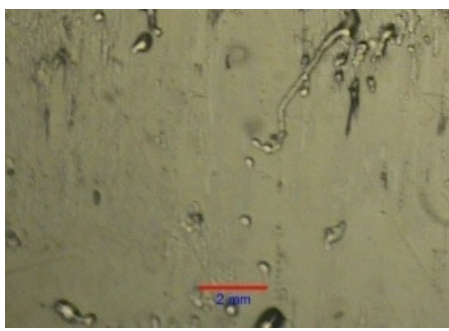

TRIS 3 wt.\%

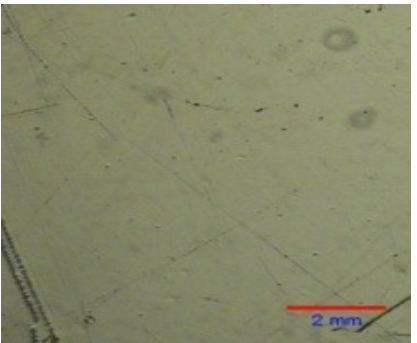

TRIS 1wt.\%

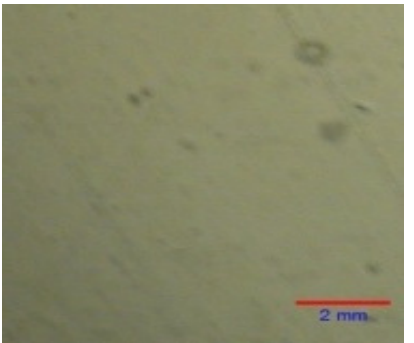

TRIS 2wt.\%

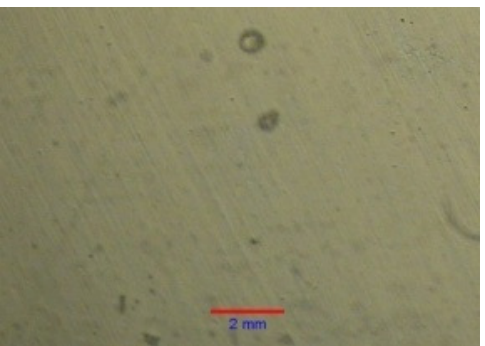

TRIS 3wt.\%

Fig. 7. Surface of PET film after the peel test (60 sec. of UV exposure time)

\section{Conclusion}

SBS type pressure sensitive adhesives for protecting optofunctionalized sheet were prepared by mixing different ratios of tackifiers of varying molecular weight and softening points. The transfer of pressure sensitive adhesive increased with increasing tackifier content and decreasing softening points of the tackifier. The degree of curing by UV increased with increasing UV exposure time and the UV curing reaction was almost complete at a UV exposure time of approximately 60 sec. In addition, the increased degree of curing caused the hardening of pressure sensitive adhesive, which decreased the peel strength and initial tack. On the other hand, the holding power of pressure sensitive adhesive increased with increasing degree of curing due to an increase in the cohesive strength of pressure sensitive adhesive.

\section{ACKNOWLEDGEMENTS}

This study was supported by Small \& Medium Business Administration of KOREA. The authors appreciated S.T. Han and Chulwoo Shin of Gyungdo Chemical Co. for their valuable support.

\section{REFERENCES}

1. C.H. Lim, Y.J. Jung and U.R. Cho, Elastom. Compos., 44, 175 (2009).

2. Y.J. Park, D.H. Lim, H.J. Kim, H.S. Song and H.J. Kwon, J. Adhesion Interf., 8, 15 (2007).

3. S. Akiyama, Y. Kobori, A. Sugisaki, T. Koyama and I. Akiba, Polymer, 41, 4021 (2000).

4. Y.W. Chang, J.B. Kim, K.H. Chung, Y.S. Chun and J.S. Jung, Elastom. Compos., 33, 267 (1998).

5. I. Nam, K. Ha, K. Lee, L.J. Kim, M. Kim, I. Seong and T. Chang, Int. J. Adhesion Adhesive, 31, 708 (2011).

6. M.K. Kang, K.A. Han and K.H. Chung, Elastom. Compos., 44, 282 (2009).

7. K.S. Yun, C.H. Sin and B.G. Myeon, Elastom. Compos., 25, 31 (1990).

8. H.S. Seo and J.S. Kang, Elastom. Compos., 3, 159 (2002).

Fig. 6. Surface of PET film after the peel test ( $20 \mathrm{sec}$. of UV exposure time) 